\title{
A FUNÇÃO SOCIAL DAS INSTITUICÕES PARTICULARES DE ENSINO SUPERIOR NO CENÁRIO EDUCACIONAL BRASILEIRO
}

\author{
Fernando de Sousa Santana ${ }^{1}$ \\ ${ }^{1}$ Professor Universitário. Mestre em Administração de Empresas e discente do Programa de Doutorado em Economia da Universidade \\ Nacional de Córdoba - UNC.
}

\section{RESUMO}

O presente artigo tem como principal objetivo tecer uma reflexão sobre a importância e a essencialidade da rede privada de Educação Superior perante o cenário educacional brasileiro. Baseando-se em investigação sobre a natureza e o papel das instituições particulares, este estudo se empenhou em fazer uma breve explanação sobre a intervenção da iniciativa privada na expansão do Ensino Superior no Brasil, além de averiguar e expor dados dos processos de avaliação da qualidade do ensino desse segmento. A pesquisa teve caráter exploratório e visou, principalmente, por meio de análise das avaliações realizadas pelo Instituto Nacional de Estudos e Pesquisas Educacionais Anísio Teixeira (INEP), Ministério da Educação (MEC), verificar a função da rede privada de Ensino Superior no contexto social brasileiro. É possível inferir, dentre outras conclusões que, as instituições privadas desoneram o governo brasileiro de suas responsabilidades, permitem uma rápida democratização da educação, proporcionando oportunidades àqueles que não conseguem ingressar nas instituições públicas, e atendem a demanda do mercado de trabalho, que busca profissionais competentes, capacitados e em constante formação.

Palavras - chave: instituições particulares de Ensino Superior, qualidade, função social.

\section{THE SOCIAL ROLE OF PRIVATE INSTITUTIONS OF HIGHER EDUCATION IN THE BRAZILIAN EDUCATIONAL SCENARIO}

\begin{abstract}
This article has as main objective to make a consideration about the importance and essentiality of private higher education based on the Brazilian educational scenario. Relying on an investigation into the nature and role of private institutions, this study sought to make a short reasoning of the involvement of private enterprise in higher education expansion in Brazil, well as investigate and expose data from the evaluation of education quality in this segment. The research was exploratory and aimed, primarily through analysis of the assessments made by the National Institute of Educational Studies Anisio Teixeira (INEP), Ministry of Education (MEC), verify the role of private higher education in the Brazilian social context. We can display, among other conclusions, the private institutions unburden the Brazilian government of its responsibilities, allow a rapid democratization of education, providing opportunities to those who cannot join in public institutions, and meet the demand of the labor market, seeking competent professionals, trained and constantly training.
\end{abstract}

Keywords: private institutions of higher education, quality, social function. 


\section{INTRODUÇÃO}

As proeminentes exigências dos consumidores têm requerido um grande esforço de adaptação e de atualização por parte das empresas que, independentemente do setor que ocupam, têm notável desempenho em melhor gerenciar seus bens e recursos na tentativa de se preservar no mercado e conquistar novos clientes.

O setor de educação também tem sido submetido a essa pressão. O nível de demanda de clientes e o potencial desse mercado ainda favorecem as escolas, entretanto, as avaliações, promovidas pelo INEP (Instituto Nacional de Estudos e Pesquisas Educacionais Anísio Teixeira), para aferir a qualidade das instituições de Ensino Superior (IES) e avaliar o ensino, o corpo docente, o prestígio e a infraestrutura disponibilizada pelas mesmas, estabelecem, claramente, os diferenciais desse setor. Portanto, oferecer produtos, cursos e serviços de qualidade se tornou, antes de qualquer coisa, uma condição para a sobrevivência e o crescimento dessas organizações de ensino.

Neves (2000) ao discorrer sobre essa questão, ressalta que vários mecanismos de avaliação foram utilizados nas últimas décadas, mas, em âmbito nacional, ainda não é possível formar uma imagem fidedigna dos cursos de graduação oferecidos, devido ao fato de não haver um processo de avaliação que possibilite aferir adequadamente sua qualidade, pois a graduação no Brasil, oferecida por instituições privadas ou públicas, está sujeita a controles do Ministério da Educação (MEC), mas apenas no que diz respeito à criação e ao reconhecimento de cursos, não havendo, contudo, nenhum tipo de acompanhamento institucionalizado para os cursos e para as escolas de nível superior em funcionamento no país (NEVES, 2000). As novas necessidades, provenientes da evolução da sociedade como um todo, demonstram que se faz necessária uma ação mais ampla, que seja direcionada ao sistema de ensino de graduação em geral.

As universidades brasileiras, em especial as particulares com finalidades lucrativas, estão passando por uma fase de questionamentos quanto à finalidade, à eficiência, à eficácia e à qualidade dos cursos que oferecem.

Em meados da década de 1990, questões relacionadas com a ética e a eficácia da ação governamental já eram discutidas e tinham como principal foco o papel do Estado em relação à educação, é o que salienta Souto-Maior apud Neves (2000). Ainda hoje, muitas críticas são feitas, algumas sem fundamento, mas que provocam movimentos de ebulição acerca dos resultados das avaliações, promovidas pelo MEC.

As escolas superiores, em geral, exercem um papel importante na sociedade, entretanto, as instituições particulares vêm sendo veementemente criticadas por serem empresas que organizam suas estruturas físicas e pedagógicas apenas em busca de aumentar o valor do capital de seus proprietários e por condicionarem a eficiência de suas organizações à independência do poder público. Em troca dos serviços prestados, que desoneram a administração pública de parte de suas responsabilidades pela educação, as instituições privadas reivindicam, com frequência, que esse mesmo governo não interfira no modo como elas se organizam, na maneira como administram o ensino e principalmente nos critérios de fixação e reajuste de mensalidades. Para essas organizações, a razão é simples: por dependerem exclusivamente do pagamento dos alunos para sobreviverem, e não de verbas governamentais, a qualidade e extensão dos serviços, por elas prestados, estão diretamente vinculados à autonomia na gerência dos custos, principalmente, no que diz respeito à captação das mensalidades (SILVA, 2001) 
Dentro desse contexto, o presente artigo visa discutir qual a função exercida pelas instituições particulares de Ensino Superior na sociedade brasileira.

\section{O PROCESSO DE EXPANSÃO DO ENSINO} SUPERIOR NO BRASIL

Segundo Masetto (1998), no século XVII e início do XIX, os brasileiros que se interessavam por cursar universidades tinham que estudar em Portugal ou em outros países europeus, pois somente uma pequena parte da população - a elite brasileira - tinha condições de sair do país para buscar profissionalização e formação intelectual e política.

Mas, sob a ótica de Paula (2005), a vinda da família real, em 1808, marcou a história das universidades no Brasil, a partir do momento em que o país passou a ser sede da coroa portuguesa, sendo possível afirmar que mudanças radicais ocorreram na educação e que, desde então, há uma evolução contínua no ensino universitário.

Para a constituição de uma infraestrutura necessária ao funcionamento do império, foram implementadas medidas administrativas, econômicas e culturais que transformaram o país. Nesse período foram criados os primeiros estabelecimentos de ensino superior, que visavam qualificar, para realizarem serviços públicos voltados à administração do país, os indivíduos oriundos de famílias bem situadas economicamente ou que, pelo menos, apresentavam títulos (comprados ou não). Ainda em 1808, foram criados os primeiros estabelecimentos de ensino médico-cirúrgico em Salvador e no Rio de Janeiro (PAULA, 2005).

Em penadas firmes, então, ele criou a Escola Médica da Bahia (1808), a Escola de Medicina do Rio de Janeiro (1809), a Escola Nacional de Engenharia (1810), um curso de ensino agrícola (1812) e outro de farmácia (1814), ambos na Bahia; em 1816 no Rio, fundava-se a Escola de Belas Artes. Todas essas escolas atraíram cátedras (de química, botânica, filosofia, economia, política e outras). Por isso Dom João VI não poupou suas cartas régias de atos, instruções e exigências para que essas instituições não existissem apenas no papel, mas que funcionassem efetivamente. 2004, p.14)

(BOAS,

Aproximadamente em 1880, houve uma forte influência da Igreja Católica, que defendia a criação de uma universidade com supremacia religiosa que ajudasse a aumentar o quadro de intelectuais a serviço do projeto religioso. Enquanto isso, grupos políticos, como os liberais, ofereciam um programa inteiramente diferenciado dos católicos, dando prerrogativa aos setores jurídicos de estudo e às áreas das ciências humanas. Esse axioma não estaria vinculado aos compromissos religiosos e procuraria garantir as formas de autoridade e de pensamento gerados pela Revolução Francesa e pela Revolução Industrial (LEITE et al., 1998).

Ainda segundo Leite et al. (1998), outro grupo, denominado positivista, defendia idéias contrárias às duas posições anteriores, argumentando que o Brasil não precisava de universidades, mas necessitava de ensino fundamental para a população em geral, sobretudo no campo tecnológico.

De acordo com Ramacciotti, Itelvino e Barbosa (2005), a implementação de universidades foi vastamente debatida por variados grupos sociais no país, no entanto, somente no século $X X$ surgiu a primeira universidade genuinamente brasileira. De acordo com muitos historiadores, o nascimento de 
algumas universidades denotou o desvio de recursos financeiros para os estados, local de prestígio político e de emprego para os filhos das elites (FÁVERO, 1988). Já nesse período, alguns grupos tentavam fazer do ensino uma fonte de renda e de prestígio para satisfazer os seus interesses.

Consequentemente, na cultura das organizações educacionais, formas de pensar e agir também marcaram o tempo do império. Inovações nas universidades, por exemplo, foram incentivadas, muitas vezes, por Dom Pedro II que, consciente da necessidade de modernizar a ciência e a tecnologia da colônia e estimulado pelas novidades que observava em suas viagens pela Europa, trazia modelos e profissionais para reformular instituições do país.

Outro fato importante a ser citado é a reforma universitária que, promulgada pelo governo militar em 1968, é ponderada como um grande marco na história das universidades brasileiras. A Lei 5.540/68, que regulava essa reforma, inseriu a relação custo-benefício e o capital humano na educação, voltando a universidade para o mercado de trabalho, aumentando o acesso da classe média ao ensino superior e restringindo a autonomia universitária.

Garante Ramacciotti, Itelvino e Barbosa (2005) que, para alcançar as metas supramencionadas, diversas medidas foram tomadas e, dentre elas, pode-se citar:

a) a unificação do vestibular por região;

b) o ingresso por classificação;

c) 0 estabelecimento de limite no número de vagas por curso;

d) a criação de um curso básico, que reune disciplinas afins em um mesmo departamento;

e) o oferecimento de cursos diferentes em um mesmo espaço, proporcionando custos menores com materiais e sem aumentar o número de professores;

f) e o estabelecimento de matrículas por disciplina.

Ao examinar os registros históricos, é possível constatar que, há tempos, a sociedade entra em conflito com as universidades, que realizam reflexões e autocríticas, para, então, reformar-se. Hoje, no que diz respeito a sua função como instituição social, a universidade provoca expectativas na sociedade brasileira e essas perspectivas delegam aos cursos de graduação a função de preparar profissionais competentes para engajá-los no mercado de trabalho.

Os desafios competitivos do mercado do século $X X I$, no qual se verifica mudanças de parâmetros, tecnologias e forças de trabalho, exigem que as universidades e seus colaboradores desempenhem novos papéis e demonstrem competências inéditas. A atual realidade competitiva demanda uma nova maneira de ver a metodologia, as funções e os profissionais da educação (OLIVEIRA, 2002).

Essas tendências exigem mudanças organizacionais radicais, forçando as empresas e a sociedade a reverem seus paradigmas tradicionais. As empresas, em particular, buscam desenvolver novas formas organizacionais, com 0 objetivo de se adaptarem às ameaças e oportunidades do novo macro ambiente econômico.

No centro dessa turbulência está um fluxo de novas tecnologias e mercados consumidores altamente competitivos e, cada vez mais, exigentes e diversificados em suas necessidades e preferências.

Sendo assim, um dos aspectos que merece ser destacado na expansão do ensino superior brasileiro é a considerável participação da rede particular nesse processo, ocorrido, principalmente, a partir do final dos anos 70 . 
Ao contrário das primeiras instituições, que surgiram próximas aos campos do poder econômico e político, as universidades particulares, de maneira geral, apareceram equidistantes das expectativas e dos grupos que ocupavam posições dominantes nessas áreas. Essas organizações passar a existir a partir da iniciativa daqueles que atuavam no setor educacional, aproveitando um momento em que o Estado, após o golpe de 1964, cedeu espaço para a iniciativa privada, visando a atender à crescente demanda de acesso ao ensino de terceiro grau (SILVA, 2001).

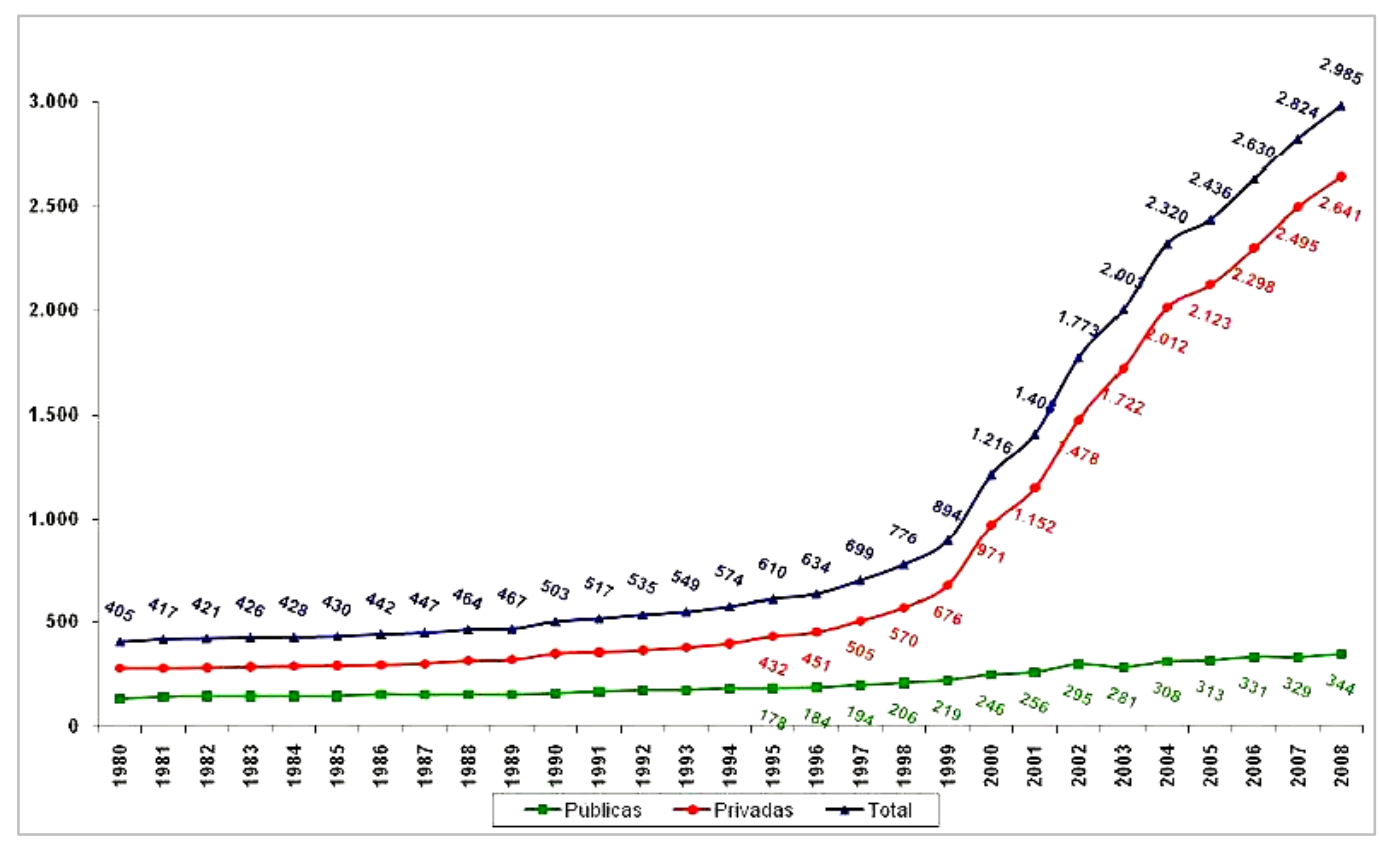

Figura 01 - Número de vagas ofertadas pelo ensino superior no Brasil Fonte: BRASIL. MEC/INEP, IBGE, SINDATA/SEMESP, OCDE (2009)

Destaca Palleta (2001) que, já no início da década de 80, o sistema particular passou a ser responsável por aproximadamente 79\% dos alunos, ficando o sistema público com o restante. Pesquisas realizadas pelo MEC (2009) evidenciam que, de 1998 a 2008, o número de vagas ofertadas em instituições privadas de Ensino Superior cresceu 363\%, enquanto nas organizações públicas esse crescimento foi de apenas $67 \%$, conforme pode ser observado pela figura 01, acima (BRASIL, 2009).

\begin{tabular}{|c|c|c|c|c|c|c|c|c|c|c|c|c|}
\hline \multirow{2}{*}{ Ano } & \multirow{2}{*}{ Total } & \multirow{2}{*}{$\% \Delta$} & \multicolumn{8}{|c|}{ Pública } & \multirow{2}{*}{ Privada } & \multirow{2}{*}{$\% \Delta$} \\
\hline & & & Total & $\% \Delta$ & Federal & $\% \Delta$ & Estadual & $\% \Delta$ & Municipal & $\% \Delta$ & & \\
\hline 2002 & 1.637 & - & 195 & - & 73 & - & 65 & - & 57 & - & 1.442 & - \\
\hline 2003 & 1.859 & 13,6 & 207 & 6,2 & 83 & 13,7 & 65 & 0,0 & 59 & 3,5 & 1.652 & 14,6 \\
\hline 2004 & 2.013 & 8,3 & 224 & 8,2 & 87 & 4,8 & 75 & 15,4 & 62 & 5,1 & 1.789 & 8,3 \\
\hline 2005 & 2.165 & 7,6 & 231 & 3,1 & 97 & 11,5 & 75 & 0,0 & 59 & $-4,8$ & 1.934 & 8,1 \\
\hline 2006 & 2.270 & 4,8 & 248 & 7,4 & 105 & 8,2 & 83 & 10,7 & 60 & 1,7 & 2.022 & 4,6 \\
\hline 2007 & 2.281 & 0,5 & 249 & 0,4 & 106 & 1,0 & 82 & $-1,2$ & 61 & 1,7 & 2.032 & 0,5 \\
\hline 2008 & 2.252 & $-1,3$ & 236 & $-5,2$ & 93 & $-12,3$ & 82 & 0,0 & 61 & 0,0 & 2.016 & $-0,8$ \\
\hline
\end{tabular}


Figura 02 - Evolução do número de instituições, por categoria administrativa - Brasil - 2002 a 2008 Fonte: BRASIL. MEC/INEP/DEED (2009).

Além disso, dados recentes, também apresentados pelo MEC (2009), demonstram a consolidação da participação do sistema privado no processo expansionista da educação brasileira, conforme pode ser observado na figura 02, que inclui todas as IES que oferecem cursos de graduação - presencial e a distância.

Em um mundo em que os recursos cognitivos se tornaram preponderantes perante os recursos materiais, a importância do Ensino Superior também aumentou na mesma celeridade. Por conseguinte, em face das inovações e do desenvolvimento tecnológico, a economia exige, a cada dia, mais profissionais competentes, habilitados e com nível superior
(NOSELLA, 2002). Sendo assim, essas condições são fundamentais para quem quer conquistar um bom posto de trabalho e foi o que incentivou multidões de jovens a voltarem aos bancos escolares, ao longo dos últimos 30 anos.

Parte desse retorno às instituições de ensino pode ser verificado na figura 03 , que representa, de acordo com dados do MEC (2009), a evolução do número de concluintes de cursos superiores no Brasil, de 2002 a 2008. A partir dos dados apresentados, mais uma vez, é possível perceber a superioridade do número de alunos das instituições privadas, em relação àqueles das universidades públicas.

\begin{tabular}{|c|c|c|c|c|c|c|c|c|c|c|c|}
\hline \multirow{2}{*}{\multicolumn{2}{|c|}{ Ano e localização }} & \multirow{2}{*}{ Total } & \multirow{2}{*}{$\% \Delta$} & \multicolumn{5}{|c|}{ Pública } & \multirow{2}{*}{$\% \Delta$} & \multirow{2}{*}{ Privada } & \multirow{2}{*}{$\% \Delta$} \\
\hline & & & & Federal & $\% \Delta$ & Estadual & $\% \Delta$ & Municipal & & & \\
\hline \multirow[t]{3}{*}{2.002} & Total & $4 \quad 466.260$ & _ & 71.285 & & 63.917 & & 15.899 & - & 315.159 & \\
\hline & Capital & 201.692 & - & 47.359 & - & 14.767 & 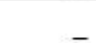 & & - & 139.566 & - \\
\hline & Interior & 264.568 & - & 23.926 & - & 49.150 & - & 15.899 & - & 175.593 & - \\
\hline \multirow[t]{3}{*}{2.003} & Total & 528.223 & 17,2 & 84.341 & 18,3 & 65.375 & 2,3 & 19.443 & 22,3 & 359.064 & 12,2 \\
\hline & Capital & 228.905 & 13,5 & 54.066 & 14,2 & 15.950 & 8,0 & 124 & & 158.765 & 12,1 \\
\hline & Interior & 299.318 & 4,8 & 30.275 & 26,5 & 49.425 & 0,6 & 19.319 & $21, \overline{5}$ & 200.299 & 12,3 \\
\hline \multirow[t]{3}{*}{2.004} & Total & 626.617 & 18,6 & 88.098 & 4,5 & 93.152 & 42,5 & 21.012 & 8,1 & 424.355 & 15,4 \\
\hline & Capital & 266.085 & 16,2 & 54.008 & $-0,1$ & 16.642 & 4,3 & 209 & 68,5 & 195.226 & 18,7 \\
\hline & Interior & 360.532 & 20,5 & 34.090 & 12,6 & 76.510 & 54,8 & 20.803 & 7,7 & 229.129 & 12,6 \\
\hline \multirow[t]{3}{*}{2.005} & Total & 717.858 & 14,6 & 86.011 & $-2,4$ & 87.676 & $-5,9$ & 21.867 & 4,1 & 522.304 & 18,8 \\
\hline & Capital & 307.708 & 15,6 & 55.867 & 3,4 & 19.726 & 18,5 & 195 & $-6,7$ & 231.920 & 15,8 \\
\hline & Interior & 410.150 & 13,8 & 30.144 & $-11,6$ & 67.950 & $-11,2$ & 21.672 & 4,2 & 290.384 & 21,1 \\
\hline \multirow[t]{3}{*}{2.006} & Total & 736.829 & 2,6 & 83.686 & $-2,7$ & 76.516 & $-12,7$ & 22.883 & 4,6 & 553.744 & 5,7 \\
\hline & Capital & 319.405 & 3,8 & 55.317 & $-1,0$ & 15.995 & $-18,9$ & 173 & $-11,3$ & 247.920 & 6,5 \\
\hline & Interior & 417.424 & 1,8 & 28.369 & $-5,9$ & 60.521 & $-10,9$ & 22.710 & 4,8 & 305.824 & 5,0 \\
\hline \multirow[t]{3}{*}{2.007} & Total & 756.799 & 2,7 & 89.257 & 6,7 & 80.014 & 4,6 & 24.260 & 6,0 & 563.268 & 1,7 \\
\hline & Capital & 323.513 & 1,3 & 57.737 & 4,4 & 15.755 & $-1,5$ & 252 & 45,7 & 249.769 & 0,7 \\
\hline & Interior & 433.286 & 3,8 & 31.520 & 11,1 & 64.259 & 6,2 & 24.008 & 5,7 & 313.499 & 2,4 \\
\hline \multirow[t]{3}{*}{2.008} & Total & 800.318 & 5,8 & 84.036 & $-5,8$ & 78.879 & $-1,4$ & 24.843 & 2,4 & 612.560 & 8,0 \\
\hline & Capital & 345.291 & 6,7 & 55.574 & $-3,7$ & 16.318 & 3,6 & 358 & 42,1 & 273.041 & 8,5 \\
\hline & Interior & 455.027 & 5,0 & 28.462 & $-9,7$ & 62.561 & $-2,6$ & 24.485 & 2,0 & 339.519 & 7,7 \\
\hline
\end{tabular}

Figura 03 - Evolução do número de concluintes, por categoria administrativa - Brasil 2002 a 2008 Fonte: BRASIL.MEC/INEP/DEED (2009). 
Para se ter uma imagem do alcance desse crescimento, em 1970, o Brasil registrava 400 mil alunos em cursos superiores. Na década de 90, esse segmento passou a atender cerca de 1 milhão de alunos, no qual a maioria provinha de uma elite intelectual. Posteriormente, esse contingente aumentou para 2,4 milhões de estudantes, no ano de 2000 (SCHWARTZMAN, 2003). E, em 2007, o número de universitários ultrapassou a marca dos 3 milhões (BRASIL, MEC, 2008).

Além disso, a Lei de Diretrizes e Bases da Educação Nacional (LDB), promulgada em 1996, conferiu maior consistência à educação, uma vez que redefiniu os papéis e as responsabilidades dos variados níveis educacionais - básico e superior - confiando maior autonomia às instituições de Ensino Superior (MARTINS, 2000).

Essas transformações fizeram do Brasil o único país do mundo no qual qualquer pessoa tem acesso, por intermédio dos meios de comunicação, às notas das avaliações sobre o desempenho das instituições e dos cursos de Ensino Superior - públicos e privados. Esse processo é realizado pelo INEP, que conduz o sistema de avaliação dos cursos superiores do país, produzindo indicadores que subsidiam o processo de regulamentação, exercido pelo MEC, além de garantir a transparência desses dados a toda a sociedade. Conforme destacou o então Ministro da Educação, Fernando Haddad, segundo a Assessoria de Comunicação Social do MEC: "Esse processo é público e deve continuar público para que haja controle social". (BRASIL, 2008).

Sendo assim, é possível observar mudanças relevantes no Ensino Superior, principalmente no tocante à expansão do sistema e sua melhoria, à avaliação da graduação e ao apoio à extensão e pós-graduação.

\section{FUNÇÕES DO ENSINO SUPERIOR}

PARTICULAR NO CONTEXTO BRASILEIRO

Inicialmente se faz necessário retornar à gênese dos fatos, para melhor discuti-los. Para tal recorremos aos conhecimentos do professor Silva, (2001), o qual destaca que desde que o Relatório Atcon $^{1}$ diagnosticou o estrangulamento no canal de acesso à universidade, a preocupação dos governos que se sucederam durante a ditadura militar foi a ampliação de vagas sem que isso representasse um investimento significativo. Com esse objetivo, firmou-se a argumentação de que o Ensino Superior privado cumpriria essa função de maneira a complementar o papel do poder público, tendo em vista a impossibilidade de o mesmo arcar completamente com esse ônus.

Segundo pesquisa do SINDATA Sistema de informações do Ensino Superior particular - realizada em 2009, o custo anual por aluno, nas instituições públicas de Ensino Superior, é estimado em R $\$ 15$ mil, considerando os pagamentos dos inativos e precatórios, e em, aproximadamente, $\mathrm{R} \$ 11$ mil, sem considerá-los. De acordo com a figura 04, se, hipoteticamente, não existisse a participação da iniciativa privada no setor de Ensino Superior brasileiro, para atingir o mesmo número de alunos matriculados até 2008, no Ensino Superior, o poder público teria investido aproximadamente $\mathrm{R} \$ 788$ bilhões desde 1960, o que equivale, aproximadamente, a 1/3 do PIB total do ano de 2008.

1 Estudo avaliativo da Educação Superior, que objetivou sintonizar a universidade brasileira com os propósitos do governo (FÁVERO, 1988). 


\section{QUANTO O PODER PÚBLICO TERIA GASTO SEM A INICIATIVA PRIVADA DESDE 1960?}

\begin{tabular}{lc}
\hline & 2008 \\
\hline PIB preços correntes em reais & $\mathrm{R} \$ 2.889 .718 .577 .035$ \\
\hline
\end{tabular}

\begin{tabular}{lcc}
\hline \multicolumn{2}{c}{ Gastos com Educação Superior desde 1960 } & $\begin{array}{c}\text { Comparativo com o } \\
\text { PIB de 2008 }\end{array}$ \\
\hline Incluindo inativos e precatórios & $\mathrm{R} \$ 788.158 .235 .460$ & $27 \%$ \\
\hline Excluindo inativos e precatórios & $\mathrm{R} \$ 577.982 .706 .004$ & $20 \%$ \\
\hline
\end{tabular}

Figura 04 - Estimativa de prováveis gastos do poder público desde 1960, se não houvesse a participação da iniciativa privada na educação.

Fonte: Banco Central e SINDATA/SEMESP (2009)

Relata Silva (2001), que a entrada da iniciativa privada no Ensino Superior deu-se, primeiramente, por meio de uma ampliação das atividades que os empresários da educação já exerciam na esfera do ensino básico. Dessa forma, a mentalidade organizacional, desse mesmo grupo, fez expandir e consolidar as empresas de ensino de primeiro e segundo graus, regendo as iniciativas privadas do ensino universitário. O objetivo foi justapor a eficiência empresarial, já comprovada no ensino básico, para o ensino universitário e marcar, também nesse nível, a superioridade organizacional da empresa particular em relação à instituição pública.

A partir de então, duas consequências de ordem propriamente política puderam ser observadas. Em primeiro lugar, a proliferação de escolas particulares de Ensino Superior permitiu o acesso de vastas camadas da classe média ao ensino universitário, atendendo, assim, as expectativas da sociedade. Em segundo lugar, o caráter próprio dessas organizações empresariais propôs perfis de cursos superiores, significativamente, distintos daqueles oferecidos em instituições públicas.

Com base no exposto, é o possível perceber que o poder público encontrou vantagens na expansão do ensino privado, pois funcionou como um meio de desonerar sua responsabilidade educativa e como um instrumento ideológico eficaz, que colaborou com a adaptação do alunado às regras de comportamento político (ou apolítico) vigentes.

Além disso, é importante destacar que a condição socioeconômica, do aluno, sempre pareceu representar papel decisivo no ingresso em várias carreiras das universidades públicas mais bem conceituadas. O problema não é estritamente relacionado ao gasto público, porque o Brasil figura entre os países que mais destinam verbas para educação, mas, na realidade, há uma inversão de prioridades, em prejuízo do ensino fundamental e médio. Em um país de renda média como o Brasil, com persistência de grandes bolsões de pobreza, o Ensino Superior público, paradoxalmente, tem favorecido a camada mais rica da população.

Em contrapartida, cumpre-nos ressaltar, ainda, que a expansão do Ensino Superior particular permitiu uma rápida democratização da educação brasileira, pois, a partir desse advento, o acesso à universidade passou a independer de condições socioeconômicas e os novos critérios de ingresso já não favoreciam apenas aqueles que detinham situação privilegiada. 
De acordo com Figueiredo (2010), dados da Pesquisa Nacional por Amostra de Domicílios (PNAD), indicam que 93\% dos estudantes nas IES públicas estão entre os 40\% mais ricos da população e que $73 \%$ desses mesmos alunos estão entre os $20 \%$ mais ricos do país.

Outro dado a se considerar, no processo de democratização do Ensino Superior, diz respeito ao horário em que os cursos superiores são ofertados. Apesar do recente crescimento dos cursos noturnos, o ensino federal é ainda, predominantemente, diurno, com somente $21 \%$ dos estudantes em cursos noturnos, contra $67 \%$ no ensino privado. A figura 05, apresentada a seguir, divulga informações do MEC (2009) capazes de ilustrar essa diferenciação.

O ensino público brasileiro sempre optou por ser um sistema seletivo, que restringe a entrada de alunos menos qualificados, que requer dedicação exclusiva para os estudos e que reprova aqueles que não conseguem passar nos exames. Em compensação, a iniciativa privada acolhe um número cada vez maior de estudantes mais velhos e que precisam de horários flexíveis para trabalhar, além de atender a um crescente grupo de alunos que emanam de um ensino secundário precário.

\begin{tabular}{|c|c|c|c|c|c|c|c|c|c|c|c|}
\hline \multirow{2}{*}{\multicolumn{2}{|c|}{ Ano e localização }} & \multirow{2}{*}{ Total } & \multirow{2}{*}{$\% \Delta$} & \multicolumn{5}{|c|}{ Pública } & \multirow{2}{*}{$\% \Delta$} & \multirow{2}{*}{ Privada } & \multirow{2}{*}{$\% \Delta$} \\
\hline & & & & Federal & $\% \Delta$ & Estadual & $\% \Delta$ & Municipal & & & \\
\hline \multirow[t]{3}{*}{2002} & Total & 466.260 & - & 71.285 & - & 63.917 & - & 15.899 & - & 315.159 & \\
\hline & Diurno & 193.737 & - & 55.080 & - & 37.030 & - & 2.964 & - & 98.663 & - \\
\hline & Noturno & 272.523 & - & 16.205 & - & 26.887 & - & 12.935 & - & 216.496 & 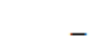 \\
\hline \multirow[t]{3}{*}{2003} & Total & 528.223 & 13,3 & 84.341 & 18,3 & 65.375 & 2,3 & 19.443 & 22,3 & 359.064 & 13,9 \\
\hline & Diurno & 218.615 & 12,8 & 64.917 & 17,9 & 39.330 & 6,2 & 4.386 & 48,0 & 109.982 & 11,5 \\
\hline & Noturno & 309.608 & 13,6 & 19.424 & 19,9 & 26.045 & $-3,1$ & 15.057 & 16,4 & 249.082 & 15,1 \\
\hline \multirow[t]{3}{*}{2004} & Total & 626.617 & 18,6 & 88.098 & 4,5 & 93.152 & 42,5 & 21.012 & 8,1 & 424.355 & 18,2 \\
\hline & Diurno & 257.698 & 17,9 & 67.251 & 3,6 & 61.953 & 57,5 & 4.629 & 5,5 & 123.865 & 12,6 \\
\hline & Noturno & 368.919 & 19,2 & 20.847 & 7,3 & 31.199 & 19,8 & 16.383 & 8,8 & 300.490 & 20,6 \\
\hline \multirow[t]{3}{*}{2005} & Total & 717.858 & 14,6 & 86.011 & $-2,4$ & 87.676 & $-5,9$ & 21.867 & 4,1 & 522.304 & 23,1 \\
\hline & Diurno & 272.923 & 5,9 & 65.822 & $-2,1$ & 54.408 & $-12,2$ & 4.944 & 6,8 & 147.749 & 19,3 \\
\hline & Noturno & 444.935 & 20,6 & 20.189 & $-3,2$ & 33.268 & 6,6 & 16.923 & 3,3 & 374.555 & 24,6 \\
\hline \multirow[t]{3}{*}{2006} & Total & 736.829 & 2,6 & 83.686 & $-2,7$ & 76.516 & $-12,7$ & 22.883 & 4,6 & 553.744 & 6,0 \\
\hline & Diurno & 270.403 & $-0,9$ & 63.969 & $-2,8$ & 44.871 & $-17,5$ & 5.189 & 5,0 & 156.374 & 5,8 \\
\hline & Noturno & 466.426 & 4,8 & 19.717 & $-2,3$ & 31.645 & $-4,9$ & 17.694 & 4,6 & 397.370 & 6,1 \\
\hline \multirow[t]{3}{*}{2007} & Total & 756.799 & 2,7 & 89.257 & 6,7 & 80.014 & 4,6 & 24.260 & 6,0 & 563.268 & 1,7 \\
\hline & Diurno & 279.819 & 3,5 & 67.956 & 6,2 & 49.922 & 11,3 & 6.032 & 16,2 & 155.879 & $-0,3$ \\
\hline & Noturno & 476.980 & 2,3 & 21.271 & 7,9 & 30.092 & $-4,9$ & 18.228 & 3,0 & 407.389 & 2,5 \\
\hline \multirow[t]{3}{*}{2008} & Total & 800.318 & 5,8 & 84.036 & $-5,8$ & 78.879 & $-1,4$ & 24.843 & 2,4 & 612.560 & 8,8 \\
\hline & Diurno & 284.697 & 1,7 & 64.031 & $-5,8$ & 49.374 & $-1,1$ & 6.126 & 1,6 & 165.166 & 6,0 \\
\hline & Noturno & 515.621 & 8,1 & 20.005 & $-6,0$ & 29.505 & $-2,0$ & 18.717 & 2,7 & 447.394 & 9,8 \\
\hline
\end{tabular}

Figura 05 - Evolução do número de concluintes, por categoria administrativa, segundo o turno - Brasil 2002 a 2008

Fonte:BRASIL.MEC/INEP/DEED (2009)

Sendo assim, as instituições particulares de Ensino Superior enfrentam o desafio de proporcionar um ensino de qualidade e apropriado a esse novo público, em contrapartida aos modelos mais tradicionais. Esse sistema de Ensino Superior deve oferecer: cursos de curta 
duração, de dois ou três anos, que preparem, com rapidez, o estudante para o mercado de trabalho; sistemas de educação continuada; cursos de formação geral; vinculações mais estreitas entre o mundo do trabalho e o do estudo; e uso intensivo dos novos instrumentos de educação à distância.

Segundo Sguissardi (2003), ocorreu, em certa medida, um processo de estreita aproximação entre o mercado capitalista e o Ensino Superior, o que é corroborado pelas elites da política brasileira, conforme demonstrando na transcrição de parte do discurso de abertura do Nono Congresso Nacional de Iniciação Científica (CONIC), proferido pelo então presidente Lula, segundo Gabriel Mario Rodrigues, da Associação Brasileira de Mantenedoras de Ensino Superior (ABMES):

A verdade é que o Estado não
cumpriu as suas obrigações.
Graças a Deus houve
empresários neste país que
tiveram coragem de fazer
investimento. Se não fosse o
ensino privado, r a
incompetência do Estado
brasileiro de investir na
educação nos levaria a ter
apenas uma pequena elite
paulistana estudando em
universidade. (SILVA, Luiz
Inácio Lula da, apud
RODRIGUES, 2009)

A sociedade depende de instituições de Ensino Superior que proporcionem, aos discentes, formações compatíveis com a nova configuração do mercado de trabalho e é nesse sentido que o segmento particular de Ensino Superior se tornou tão importante para o desenvolvimento da coletividade.

\section{A QUALIDADE DO ENSINO SUPERIOR PARTICULAR BRASILEIRO}

Atualmente, o número de instituições de Ensino Superior autorizadas a funcionar no país cresce de maneira descomedida. Sendo assim, para alcançarem o crescimento e o sucesso, as grandes universidades particulares precisam investir na qualidade e na diferenciação dos serviços prestados. Esse fato tem provocado, inevitavelmente, certo nível de confronto direto entre a concorrência, ou seja, no momento, há um acirramento do nível concorrencial, principalmente em regiões com grande número de escolas. A partir desse enfoque, é possível perceber que, para o sistema particular, oferecer cursos de qualidade é, antes de tudo, um requisito para sua sobrevivência no mercado de trabalho.

Os processos adotados pelo MEC para avaliar as instituições de Ensino Superior, objetivam aferir a qualidade dos cursos ofertados, mas essas avaliações são, relativamente, limitadas, pois não abarcam as deficiências na formação anterior dos alunos. A esse respeito, é importante reconhecer que a formação escolar é um processo cumulativo, de tal modo que as escolas públicas, por oferecerem ensino gratuito, optam por estratégias de seleção que escolhem apenas aqueles alunos mais bem preparados e que, consequentemente, destacam-se nas referidas avaliações. Nesse sentido, as instituições particulares de Ensino Superior abarcam a missão de formar a parcela da população que não consegue entrar no sistema público de ensino, devendo, portanto, fazer mais do que a rede pública, pois precisam ensinar mais e melhor para garantir que os seus egressos tenham condições de competir no mercado de trabalho.

O modelo de desenvolvimento educacional privado, cuja principal orientação é a formação para o mercado de trabalho, vem recebendo inúmeras críticas por parte das elites acadêmicas brasileiras, que ainda não conceberam o ensino dissociado da pesquisa. Entretanto dados, divulgados pelo MEC (2009), que fazem uma comparação entre a rede pública e a rede privada de educação superior, 
demonstram, cabalmente, maior satisfação dos egressos dessa última, em relação à primeira.

De modo geral, como é possível perceber pelas avaliações realizadas pelo INEP, as escolas privadas têm melhor infraestrutura, corpo docente engajado e atualizado, bibliotecas e laboratórios bem equipados, projetos pedagógicos atualizados, serviços eficientes e pesquisas e extensões - aplicadas à graduação considerados equivalentes àquelas que são oferecidas pela rede pública. Ou seja, pode-se ponderar que a qualidade proporcionada pela graduação da rede privada de educação superior é bastante similar aos atributos da rede pública.
Essa ascendência da educação particular pode ser comprovada pelas taxas de empregabilidade dos egressos de escolas privadas, conforme demonstrado pela figura $06, \mathrm{a}$ seguir, que ilustra dados obtidos por meio do anuário do Sindicato das Entidades Mantenedoras de Estabelecimentos de Ensino Superior no Estado de São Paulo (SEMESP), ano 2008. Analisando a imagem, é possível perceber que o ensino particular é o principal responsável pela formação universitária da maioria dos quadros de funcionários das maiores empresas do estado de São Paulo.

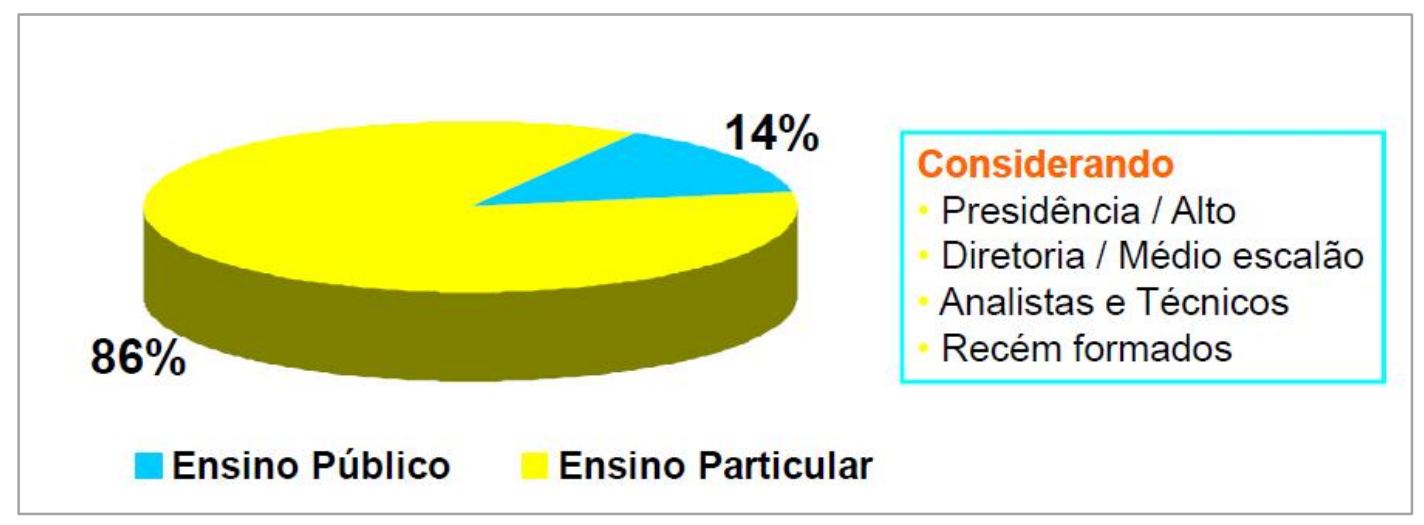

Figura 06 - Formação educacional dos funcionários das 500 maiores empresas do estado de São Paulo Fonte: Dados do anuário do SEMESP (2008).

Estudos apresentados por Figueiredo (2006) demonstram que embora muitas pessoas acreditem que as IES públicas apresentam qualidade melhor do que as instituições particulares, essa percepção se dá quase que exclusivamente em função da imagem e da marca das instituições públicas, sendo poucos os casos em que são apontados requisitos objetivos de superioridade.

Diante do exposto, os parâmetros de avaliação da qualidade do Ensino Superior particular devem reconhecer a importância e a essencialidade da rede privada de educação superior e renunciar aos diagnósticos e às soluções que argumentam que a rede pública é melhor perante a rede particular, afinal, esse contexto é eivado de preconceitos e ideologias que, hoje, não têm lugar fora dos livros de história.

\section{CONSIDERAÇÕES FINAIS}

O cerne dessa pesquisa não se reduz a competição entre o ensino ofertado pela rede pública e o oferecido pela particular, apenas é preciso compreender que ambas cumprem um papel importante perante a sociedade.

Diante das informações expostas pelo presente artigo, é possível afirmar que cabe ao Estado a responsabilidade de normatizar e proporcionar a educação à sociedade brasileira. 
Mas, diante do advento da proliferação das instituições particulares de Ensino Superior, essa função deixou de ser um monopólio do poder público, para se tornar uma relação de parceria com o setor privado, que se transformou em um participante legítimo e essencial para a concretização dessa missão.

A expansão do Ensino Superior particular é um fator de democratização, à medida que oferece oportunidades àqueles que não conseguem ingressar em instituições públicas e proporciona o acesso da parcela da população que não detêm situação socioeconômica privilegiada. Igualmente, esse sistema abarca um crescente grupo de egressos de um ensino secundário precário e, também, os estudantes que precisam de horários flexíveis para trabalhar, aproximando-os do mercado de trabalho.

Em suma, o perfil do aluno no Ensino Superior privado, inclui "[...] jovens recémegressos do curso secundário, pessoas mais velhas, já empregadas, que não tinham oportunidade de estudar e que viam no Ensino Superior uma possibilidade de melhoria no mercado ocupacional" (SAMPAIO, 2000, p. 63).

O concorrente mercado de trabalho apresenta contínuas mudanças e recorrente acirramento de suas exigências e, em meio a esse cenário competitivo, as instituições de ensino agregam inúmeros desafios. Essas disposições exigem que as organizações particulares revejam seus padrões e se modifiquem para acompanhar, inovar e atender as necessidades que a sociedade demanda, se fazendo necessário que elas se adaptem ao mercado para garantir sua sobrevivência.

A afirmação de que os empreendimentos educacionais visam ao lucro é procedente, mas, diante dos motivos supracitados, não deve ser percebida como uma circunstância adversa à finalidade do ensino, pois os investimentos na educação, realizados pelo setor privado, são traduzidos em benefícios para a sociedade em geral.

Atualmente, as instituições de Ensino Superior são avaliadas e questionadas por órgãos competentes do governo, que fiscalizam a qualidade e os resultados dessa parceria. É imponente perceber que, atualmente, as instituições de ensino deixaram de assimilar a avaliação como uma penalização, para vê-la como algo positivo que colabora para sua reflexão e seu desenvolvimento.

Nesse contexto, a educação superior particular se consolida com força atuante e com renome na geração e na difusão do conhecimento. Em busca de seu lugar no mercado, as instituições particulares de Ensino Superior enfrentam o desafio de proporcionar um ensino de qualidade e apropriado às atuais exigências sociais, em contrapartida aos modelos mais tradicionais.

Pode-se destacar, então, que o papel da iniciativa privada representa um dos maiores programas de inclusão do país.

\section{REFERÊNCIAS}

BOAS, S. V.. Ensino Superior particular: um vôo histórico. São Paulo: Segmento, 2004.

BRASIL. LEI 5.540/68. Fixa normas de organização e funcionamento do Ensino Superior e sua articulação com a escola média, e dá outras providências, 28 de novembro de 1968. Disponível em: <http://www.jusbrasil.com.br/legislacao/109783/lei -5540-68>. Acesso em: 12 maio 2010.

. Ministério da Educação e Cultura. INEP.

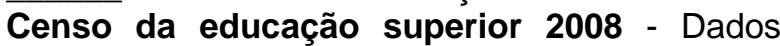
preliminares. Brasília, DF, 2009. Disponível em: <http://www.ufrgs.br/sai/dadosresultados/Avaliaca olESgeral\%5CRelatorios\%5CCensodaEducacao Superior\%5C2008\%5CCES2008ResumoTecnico. pdf>. Acesso em: 23 jun. 2009.

Ministério da Educação e Cultura.. Secretaria de Educação Superior. Programa de Avaliação das Universidades Brasileiras PAIUB. 2008. Disponível em: <www.mec.gov.br>. Acesso em: 14 abr. 2009. 
Ministério da Educação e Cultura.. O novo indicador para o Ensino Superior. 2008. Disponível em: <http://portal.mec.gov.br/index.php?option=com_c ontent\&task=view\&id=10990 > . Acesso em: 16 set. 2008.

FÁVERO, M. L. A. Ensino Superior, Universidade e a nova LDB: encaminhamento de questões. Em Aberto, Brasília, v. 7, n. 38, p. 45-50, abr./jun. 1988.

Universidade e poder: análise crítica e fundamentos teóricos. Rio de Janeiro: Achiamé, 1980.

FIGUEIREDO, F. F. Educação superior e mobilidade social: limites, possibilidades e conquistas. 2006. 241 f. Tese (Doutorado em Ciências Sociais). PUC: São Paulo.

FIGUEIREDO, H. Reflexões que vão além. Revista Ensino Superior, ed. 145, out., 2010. Disponível em: <http://revistaensinosuperior.uol.com.br/textos.as p?codigo=12669>. Acesso em: 12 nov. 2010.

LEITE, D. et al. A avaliação institucional e os desafios da formação do docente na universidade pós-moderna. In: MASETTO, M. T. (Org.). Docência na universidade. Campinas: Papirus, 1998.

MARTINS, J.R. Branding: um manual para você criar, avaliar e gerenciar marcas. São Paulo: Negócio, 2000.

MASETTO, M. T. Professor universitário: um profissional da educação na atividade docente. In: MASETTO, M. T. Docência na universidade. Campinas: Papirus, 1998.

NEVES, A. A imagem das instituições de Ensino Superior e a qualidade do ensino de graduação: a percepção dos acadêmicos do curso de administração. Paraná: UNOPAR, 2000.

NOSELLA, P. Qual compromisso político? Ensaios sobre a educação brasileira pós-ditadura. 2. ed. São Paulo: EDUSF, 2002.

OLIVEIRA, L. H. de. Alunos não são clientes. Jornal dos Lagos, Alfenas, 2002. Disponível em: <http://www.geocites.com/lucielhenrique/jornais/al unosnaoclientes>. Acesso em: 10 abr. 2008.

PALETTA, M. A. Porter e as Instituições de Ensino Superior: um estudo exploratório. 2001. Dissertação (Mestrado) - : Universidade de São Francisco, Bragança Paulista..

PAULA, L. C. A vocação auto-reflexiva da antropologia no Brasil: um retrato de sua historiografia a partir da década de oitenta. Marília, SP: UNESP , 2005.

RAMACCIOTTI, C.; ITELVINO, L. S.; BARBOSA, L. B. A profissão docente e as práticas do ensino de administração de empresas. In: ENCONTRO NACIONAL DOS CURSOS DE GRADUAÇÃO EM ADMINISTRAÇÃO, 2005, Belo Horizonte. Anais... Belo Horizonte: 2005.

RODRIGUES, G. M.. Presidente Lula enaltece a importância do setor privado de Ensino Superior. ABMESeduca.com, 2009. Disponível em: <http://www.abmeseduca.com/?p=65>. Acesso em: 20 nov. 2009.

SAMPAIO, H. M. S.. O Ensino Superior no Brasil: o setor privado. São Paulo: Hucitec, FAPESP, 2000.

SCHWARTZMAN, S. A Educação Superior. Revista Aprender, ano 3, n. 4, p. 06, 2003.

SEMESP. Pesquisa SEMESP. A força do Ensino Superior no mercado de trabalho. 2008. Disponível em: $<$ http://www.semesp.org.br/portal/pdfs/2008/pesq uisa_mercado_trabalho.pdf $>$. Acesso em: 11 maio 2010

SGUISSARDI, $\quad$ V. A universidade neoprofissional, heterônoma e competitiva. In: 26a Reunião Anual da ANPEd - Associação Nacional de Pós-Graduação e Pesquisa em Educação, p. 1-18, 2003.

SILVA, F. L. A motivação política da expansão do Ensino Superior privado: causas e consequências. Estudos Avançados, v. 15, n.42, $2001 . \quad$ Disponível em: <http://pt.scribd.com/doc/7011268/FranklinLeopoldo-Da-Silva-ReflexOes-Sobre-o-Conceitoe-a-FunCAo-Da-Universidade-pUblica>. Acesso em: 12 maio 2010. 